\title{
Geochemical Response Characteristics of Produced Water in CBM Wells and Geological significance to Development
}

YANG Zhaobiao $^{* *}$

${ }^{1}$ School of Resource and Geosciences, China University of Mining and Technology, Xuzhou Jiangsu, 221116, China;

(*Corresponence:zhaobiaoyang@163.com)

Method

The conventional cations and anions in the produced water from the Songhe coalbed methane (CBM) well group in western Guizhou Province were taken as the tracking targets to analyze the geological significance of gas-water mutual response during the production process.

\section{Discussion of results}

On the spatial scale, it is found that the contents of $\mathrm{Na}^{+}$, $\mathrm{K}^{+}$and $\mathrm{Cl}^{-}$in produced water in the structural high are low, and high at the structural low; it is the opposite for $\mathrm{HCO}_{3}^{-}$, which is consistent with water production and gas production, showing the geological phenomenon of "gas-water differentiation".

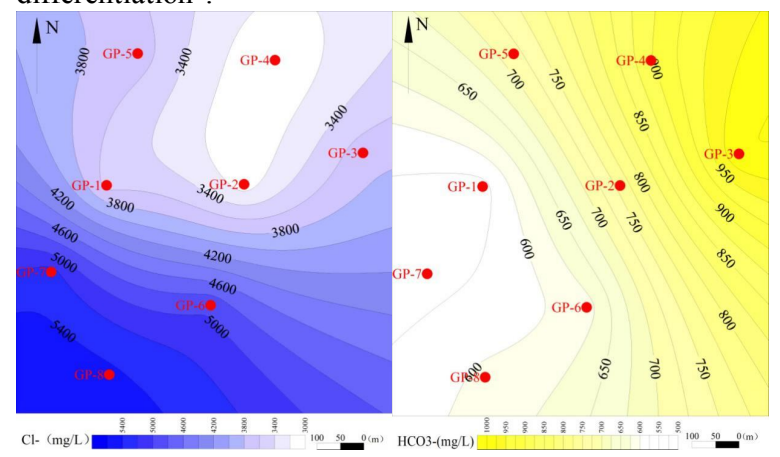

Fig. 1. Contour map of $\mathrm{Cl}^{-}, \mathrm{HCO}_{3}{ }^{-}$concentrations in October, 2016

Furthermore, major components was extracted by principal component analysis method, the index $\mathrm{F}^{*}$ characterizing the degree of groundwater closure degree was proposed, and the relationship of the $\mathrm{F}^{*}$ with $\mathrm{CBM}$ productivity was established. The smaller the $\mathrm{F}^{*}$, the higher the CBM productivity will be.

$\mathrm{F}^{*}=\left(\left[\mathrm{Na}^{+}\right]+\left[\mathrm{K}^{+}\right]+\left[\mathrm{Ca}^{2+}\right]+\left[\mathrm{Mg}^{2+}\right]+\left[\mathrm{Cl}^{-}\right]\right) /\left(\left[\mathrm{HCO}_{3}{ }^{-}\right]+\left[\mathrm{SO}_{4}{ }^{2-}\right]\right)$ 